\title{
Fabrication and Study of the Mechanical Properties of AA2024 Alloy Reinforced with $\mathrm{B}_{4} \mathrm{C}$ Nano-particles using Ultrasonic cavitation method
}

\author{
Dr.Govind Nandipati ${ }^{2}$, Dr.Ravindra kommineni², Dr.Nageswara Rao Damera ${ }^{3}$, \\ Dr.Ramanaiah Nallu'. \\ ${ }^{1}$ Associate.Professor, Department of Mechanical Engineering , R.V.R\&J.C college of Engineering, Guntur, \\ ${ }^{2}$ Professor \& Head of the Department of Mechanical Engineering, R.V.R\&J.C college of Engineering ,Guntur, \\ ${ }^{3}$ Vice chancellor Centurion University of Technology and Management, Parlakhemundi, Odisha, \\ ${ }^{4}$ Associate Professor, Department of Mechanical Engineering, Andhra university college of Engineering \\ Visakhapatnam.
}

\begin{abstract}
Metal matrix nanocomposites (MMNCs) with the addition of nano-sized ceramic particles can be of significance for automobile, aerospace and numerous other applications. The physical and mechanical characteristics of the light refractory carbides such as $\mathrm{SiC}, \mathrm{TiC}$ and $\mathrm{B}_{4} \mathrm{C}$ make them suitable for being used as reinforcement in aluminium base metal matrix composites This paper presents a technique for an inexpensive fabrication of bulk lightweight MMNCs with reproducible microstructures and superior properties by use of ultrasonic nonlinear effects, namely transient cavitation and acoustic streaming; to achieve uniform dispersion of nano-sized $B_{4} C$ particles in molten aluminum alloy. Nano-sized $B_{4} C_{p}$ enhanced properties of aluminium matrix composites, with $1.5 \%$ wt of $B_{4} C$. As compared to the base metal alloy, the mechanical properties including tensile strength and yield strength of the nanocomposites were improved significantly, while the ductility of base metal alloy matrix castings was retained. Micro structural study was carried out with an optical microscope and SEM which validates a good dispersion of nano-sized $B_{4} C_{p}$ in metal matrix. Mechanical properties of the as-cast MMNCs have been improved significantly even with a low weight fraction of nanosized $B_{4} C$.
\end{abstract}

Key Words: Metal matrix nano composites, Ultrasonic cavitaion, Boron carbide nanoparticles.

\section{Introduction}

Aluminium alloy 2024- $\mathrm{T}_{3}$ is an alloy, with copper as the primary alloying element. It is used in applications requiring high strength to weight ratio, as well as good fatigue resistance. It is weldable only through friction welding and has average machinability. Due to poor corrosion resistance, it is often clad with aluminium or $\mathrm{Al}-1 \mathrm{Zn}$ for protection.

Metal matrix composites (MMCs) are very interesting in various applications due to their improved properties. Efforts have been made to develop aluminium metal matrix nano composites in recent years due to their low density, high strength, superior creep resistance, high damping capacity and good dimensional stability. Magnesium matrix composites are excellent candidates as structural materials and have great potential in automotive and aerospace applications. Discontinuous micro-scale reinforcements such as short fibers, particles or whiskers, have been used to produce magnesium MMCs. Nano-sized SiC enhanced magnesium matrix nanocomposites $\mathrm{Mg}-2 \mathrm{Al}-1 \mathrm{SiC}$ with $2 \% \mathrm{SiC}$ and $\mathrm{Mg}-4 \mathrm{Al}-1 \mathrm{Si}$ with $2 \% \mathrm{SiC}$, were successfully fabricated by ultrasonic cavitation based dispersion of $\mathrm{SiC}$ nanoparticles in $\mathrm{Mg}$-(2,4)Al-1Si magnesium alloy melts. As compared to the magnesium alloy matrices, the mechanical properties including tensile strength and yield strength of the $\mathrm{Mg}-2 \mathrm{Al}-1 \mathrm{Si} / 2 \% \mathrm{SiC}$ and $\mathrm{Mg}-4 \mathrm{Al}-1 \mathrm{Si} / 2 \% \mathrm{SiC}$ nanocomposites were improved significantly, while the ductility of magnesium alloy matrix castings was retained [1]. The ultrasonic non-linear effects are used to disperse nano-sized $\mathrm{SiC}$ ceramic particles in AZ91D magnesium molten metal. The dispersion of nanosized ceramic particles uniformly in molten metal is done by ultrasonic nonlinear effects, namely transient cavitation and acoustic streaming, into molten aluminum alloy A356. High-resolution scanning electron microscopy (SEM), X-ray photo spectroscopy (XPS), and high-resolution X-ray diffractometer (XRD) techniques show a nearly uniform distribution and good dispersion of the $\mathrm{SiC}$ nanoparticles within the nanocomposites (MMNCs) can be of significance for automobile, aerospace and numerous other light weight applications. It also indicates that partial oxidation of $\mathrm{SiC}$ nanopartilces results in the formation of $\mathrm{SiO}_{2}$ in the matrix. Mechanical properties of the as-cast MMNCs have been improved significantly even with a low weight fraction of nano-sized $\mathrm{SiC}[2,3]$.

Ultrasonic cavitation is a best way to disperse $\mathrm{SiC}$ nanopowders in magnesium melt and for manufacturing of $\mathrm{Mg} / \mathrm{SiC}$ nanocomposites. $\mathrm{SiC}$ nanoparticles inside the matrix were mostly separated by 
magnesium. Due to the addition of nano $\mathrm{SiC}_{\mathrm{p}}$, the grain size of magnesium was refined. $\mathrm{SiC}$ nanoparticles bonded well with $\mathrm{Mg}$ matrix without forming an intermediate phase. The mechanical properties of the $\mathrm{Mg} / \mathrm{SiC}$ nanocomposites, the yield and tensile strengths, were improved significantly, while the ductility of pure magnesium was retained [4]. The yield strength and ultimate tensile strength of $\mathrm{Mg} / 2 \% \mathrm{SiC}, \mathrm{Mg}-4 \mathrm{Zn} / 1.5 \% \mathrm{SiC}$ and $\mathrm{Mg}-(2,4) \mathrm{Al}-1 \mathrm{Si} / 2 \% \mathrm{SiC}$ nanocomposites were improved significantly as compared to those of unreinforced pure magnesium, $\mathrm{Mg}-4 \mathrm{Zn}$ and $\mathrm{Mg}$ - $(2,4) \mathrm{Al}-1 \mathrm{Si}$ matrices. The good ductility of the matrices was twice that of pure Mg-4Zn [5]. Yong Yang, Xiaochun Li[6] have fabricated Bulk Al-based nanocomposites that enhanced the mechanical properties with nanosized $\mathrm{SiC}_{\mathrm{p}}$ by an ultrasonic based nanomanufacturing process. The microstructural study reveals that high-power ultrasonic cavitation is an effective method to disperse nano $\mathrm{SiC}_{\mathrm{p}}$ particles in aluminum A356 alloy which enhances the wettability between the particles and Al matrix..

Magnesium alloys--one third lighter than an equal volume of aluminum alloys--are one of the lightest metallic structural materials and are very attractive for applications in automotive and aerospace systems. The need for complex structural components of high performance magnesium materials is expected to continuously increase as automotive and aerospace industries are forced to improve the energy efficiency of their products. Nanoparticle reinforcements can increase the matrix mechanical strength by more effectively promoting particle hardening mechanisms than micron size particles. A fine and uniform dispersion of nanoparticles provides a good balance between the strengthener (non deforming particles) and inter-particle spacing effects to maximize the yield strength and creep resistance (by mechanisms such as dislocation bowing around the particles and pinning down dislocations at the particles by rapid diffusional stress relaxation at elevated temperatures) while retaining the good matrix ductility [7].

S. M.Zebarjad et al.[8] concentrated their study on the role of particle size of silicon carbide $(\mathrm{SiC})$ on dimensional stability of aluminium. $\mathrm{Al} / \mathrm{SiC}$ composites were reinforced with different sizes of $\mathrm{SiC}$ particles $(25 \mu \mathrm{m}, 50 \mu \mathrm{m}$, and $70 \mathrm{~nm})$.The results showed that for all materials, there was an increase in length as temperature increased and the temperature sensitivity of aluminum decreased in the presence of both micro- and nanosized silicon carbide and dimensional stability of $\mathrm{Al} / \mathrm{SiC}$ nanocomposite was better than the conventional $\mathrm{Al} / \mathrm{SiC}$ composites.

Different volume fractions of nano-alumina $\left(\mathrm{Al}_{2} \mathrm{O}_{3}\right)$ particles were dispersed into the $\mathrm{A} 356$ aluminum alloy by a mechanical stirrer to avoid agglomeration and for segregation of particles. The microstructural characterization of the composite samples showed uniform distribution of reinforcement, grain refinement of aluminium matrix and presence of the minimal porosity. Due to the presence of nano- $\mathrm{Al}_{2} \mathrm{O}_{3}$, significant improvement in hardness, $0.2 \%$ yield strength, UTS and ductility were observed [9].Due to the unique tailorability, aluminium composite materials have wide applications in aerospace and automotive industries. Earlier, fine particles of $\mathrm{SiC}_{\mathrm{p}}$ are to be reinforced in aluminium 6061 alloy which improve mechanical properties slightly. Due to the presence of cavities and agglomerates there is less significant improvement in the properties [10].

In recent years, Lan et al. and Yang and Li [11,12] developed a new nanomanufacturing method that combines solidification processes with ultrasonic cavitation based dispersion of nanoparticles in metal melts. Ultrasonic waves can produce transient cavitations of the order of nanoseconds, "micro-hot-spots" that can have temperatures of about $5000^{\circ} \mathrm{C}$, pressures above $1000 \mathrm{~atm}$. that distribute and disperse nano particles uniformly.

C.F.Deng et. al [13], reinforced Carbon nano tubes(CNT) in the aluminum alloy matrix with iso-static pressing followed by hot extrusion techniques. The mechanical properties are affected by carbon nano tubes content. At $1.0 \%$ wt of CNTs the mechanical properties increased and decrease at higher \%weight. The more percentage of $\mathrm{Si}$ constrains the reaction between the $\mathrm{SiC}$ and $\mathrm{Al}$ in the matrix. It is observed that viscosity of the molten metal increased due to the addition of the nano SiC particles [14].

In this paper, $\mathrm{B}_{4} \mathrm{C} / \mathrm{AA} 2024$ composites are fabricated by casting using high-intensity ultrasonic wave technique. The microstructure and microhardness of these composites are investigated.

\section{Experimental Procedure}

The base material used in this study is AA2024alumunium alloy has the following chemical composition.

Table.1 Chemical composition of AA2024

\begin{tabular}{|c|c|c|c|c|c|c|c|c|c|}
\hline $\begin{array}{c}\text { Alloy } \\
\text { element }\end{array}$ & $\mathrm{Al}$ & $\mathrm{Cu}$ & $\mathrm{Si}$ & $\mathrm{Fe}$ & $\mathrm{Mg}$ & $\mathrm{Mn}$ & $\mathrm{Cr}$ & $\mathrm{Ti}$ & $\mathrm{Zn}$ \\
\hline $\begin{array}{c}\% \text { by } \\
\text { weight }\end{array}$ & 90.7 & 4.9 & 0.5 & 0.5 & 1.8 & 0.9 & 0.1 & 0.15 & 0.25 \\
\hline
\end{tabular}

$\mathrm{B}_{4} \mathrm{C}$ nano particulate of size $50 \mathrm{~nm}$ are used in the study. $\mathrm{B}_{4} \mathrm{C}$ is selected as its density is close to the $\mathrm{Al}$, and thus there will not be any agglomeration of the particulate during the process. The experimental setup 
consists of an electrical resistance heating unit for melting the AA2024 aluminum alloy in a EN-8 steel crucible at $638^{\circ} \mathrm{C}$. The Ultrasonic transducer probe of the sonicator is dipped into the melt for sonication process. Boron carbide $\left(\mathrm{B}_{4} \mathrm{C}\right)$ particles are added at various weight percentages $[0.1 \%, 0.2 \%, 0.3 \%, 0.4 \%, 0.5 \%, 1 \%, 1.5 \%$ and $2 \%]$ to the melt during the cavitation process.

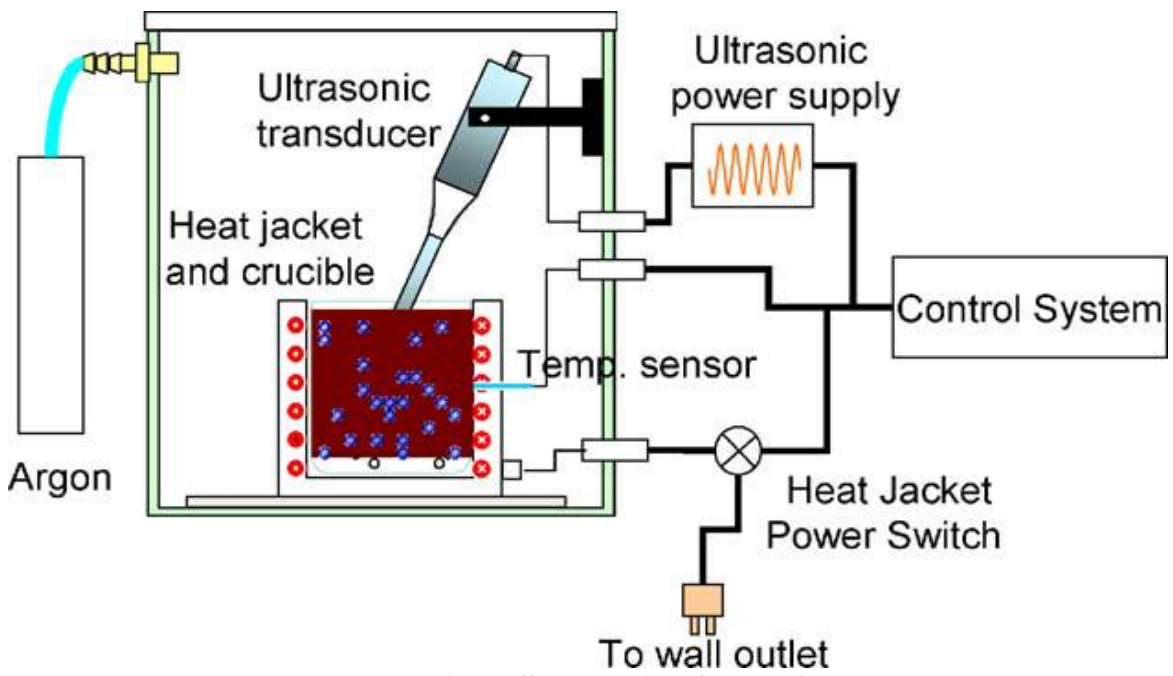

Fig.1. Schematic of experiment setup

The molten metal is protected from atmospheric air by Argon gas during melting. The metal is poured into a die of size 200x130x9 $\mathrm{mm}^{3}$ and plates are cast. The as cast plates are heat treated, (solutionised at $560^{\circ} \mathrm{c}$ for $1 \mathrm{hr}$ ) and ageing is done at $160^{\circ} \mathrm{C}$ for $12 \mathrm{hrs}$. Tensile specimens are prepared as per the ASTM-E8 standards from these plates. The heat treated plates are processed through rolling to remove the casting defects and for grain elongations. The enhanced mechanical properties of the cast plates as well as rolled sheets are observed. For Microstructural analysis MMNC cast plates are cut to size of $10 \times 10 \times 5 \mathrm{~mm}^{3}$, ground and polished to mirror finishing. The samples are etched with Keller's reagent (composed of $2 \mathrm{ml} \mathrm{HF,} 3 \mathrm{ml} \mathrm{HCl,} 5 \mathrm{ml} \mathrm{HNO}_{3}$ and $190 \mathrm{ml}$ water). Optical images and SEM images are taken to study the grain refinement and grain structures and elongations.

\section{Results And Discuscussion}

The mechanical properties and microstructures of the parent metal, the fabricated composites and rolled sheets are studied and the results are presented.

\subsection{Hardness Tests}

The nano $\mathrm{B}_{4} \mathrm{C}$ particles are added to the molten metal. While adding, the particulate tend to float on the surface of the melt. The $\mathrm{B}_{4} \mathrm{C}$ particles have a slightly lesser specific density than that of the molten aluminium alloy. As the surface tension of the melt is high, there is poor wetting between $\mathrm{B}_{4} \mathrm{C}$ particulate and the melt. By applying the high intensity ultrasonic waves, the acoustic streaming traps the nano particles into the melt effectively.

The Hardness of the MMNCs is measured at different locations on the samples. The hardness increased nearly linear with various weight percentages of the nanoB ${ }_{4} \mathrm{C}$ particulate. The hardness of the aluminum AA2024 alloy is found to be Hv-137. The hardness values of the as cast MMNCs, heat treated and after rolling are presented in the table below. The decrease of value at $2 \mathrm{wt} \%$ is due to the formation of voids and agglomerates

Table.2.Table showing the hardness values of MMNCs and after rolling

\begin{tabular}{|c|c|c|c|c|c|c|c|c|}
\hline$\%$ wt of $\mathrm{B}_{4} \mathrm{C}$ & 0.1 & 0.2 & 0.3 & 0.4 & 0.5 & 1.0 & 1.5 & 2.0 \\
\hline $\begin{array}{c}\text { Hv-of } \\
\text { MMNCs }\end{array}$ & 140 & 143 & 148 & 151 & 154 & 157 & 160 & 155 \\
\hline $\begin{array}{c}\text { Hv-after } \\
\text { rolling }\end{array}$ & 142 & 145 & 149 & 153 & 156 & 158 & 162 & 157 \\
\hline
\end{tabular}

\subsection{TENSILE TESTS:}

The tensile specimens are prepared with gauge length $28 \mathrm{~mm}$ and cross sectional area as $5 \times 6 \mathrm{~mm}^{2}$.The tests are conducted on 2Ton extensometer. The ultimate tensile strength and yield strength of the base metal 
AA2024 are found to be 420MPa and 276MPa respectively. Also the tensile tests are conducted on metal matrix nano composites and after rolling and the results presented in tables below. With only $1.5 \%$ by weight of nano $\mathrm{B}_{4} \mathrm{C}$ particles the ultimate tensile strength has been increased by $6 \%$ and reads $442 \mathrm{MPa}$. The higher dislocation density in the MMNC is responsible for strengthening mechanism. This dislocation phenomenon is due to the difference in thermal expansion coefficients between matrix and uniformly dispersed nano $\mathrm{B}_{4} \mathrm{C}$ particulate, which act as barriers for dislocation movements. The coefficient of thermal expansion mismatch the strain between the aluminum alloy metal matrix and the reinforcing nano $\mathrm{B}_{4} \mathrm{C}$ particulate. The plastic deformation of the ductile aluminum alloy metal matrix in the presence of discontinuous $\mathrm{B}_{4} \mathrm{C}$ reinforcements, is non uniform. This is due to the hard, brittle and refractory particles resisting the plastic flow of the soft, ductile and plastically deforming aluminium alloy metal matrix. The Ultimate tensile strength and Yield strength of the MMNC is increased for various wt $\%$ of nano particlesupto $1.5 \mathrm{wt} \%$ and decreased at $2 \mathrm{wt} \%$. This decrease is due to the formation of agglomerates and voids in the matrix.

Table.3. Mechanical properties of MMNCs

\begin{tabular}{|c|c|c|c|c|c|c|c|c|}
\hline$\%$ wt of $\mathrm{B}_{4} \mathrm{C}$ & 0.1 & 0.2 & 0.3 & 0.4 & 0.5 & 1.0 & 1.5 & 2.0 \\
\hline $\begin{array}{c}\text { Yield } \\
\text { strength of } \\
\text { MMNCs- } \\
\text { Mpa }\end{array}$ & 282 & 283 & 285 & 290 & 295 & 301 & 310 & 306 \\
\hline $\begin{array}{c}\text { Ultimate } \\
\text { strength of } \\
\text { MMNCs- } \\
\text { Mpa }\end{array}$ & 422 & 425 & 428 & 431 & 435 & 440 & 445 & 442 \\
\hline
\end{tabular}

Table.4. Mechanical properties of MMNCs after rolling

\begin{tabular}{|c|c|c|c|c|c|c|c|c|}
\hline$\%$ wt of $\mathrm{B}_{4} \mathrm{C}$ & 0.1 & 0.2 & 0.3 & 0.4 & 0.5 & 1.0 & 1.5 & 2.0 \\
\hline $\begin{array}{c}\text { Yield } \\
\text { strength of } \\
\text { MMNCs- } \\
\text { Mpa }\end{array}$ & 283 & 285 & 287 & 293 & 296 & 303 & 312 & 305 \\
\hline $\begin{array}{c}\text { Ultimate } \\
\text { strength of } \\
\text { MMNCs- } \\
\text { Mpa }\end{array}$ & 424 & 427 & 430 & 434 & 439 & 444 & 449 & 401 \\
\hline
\end{tabular}

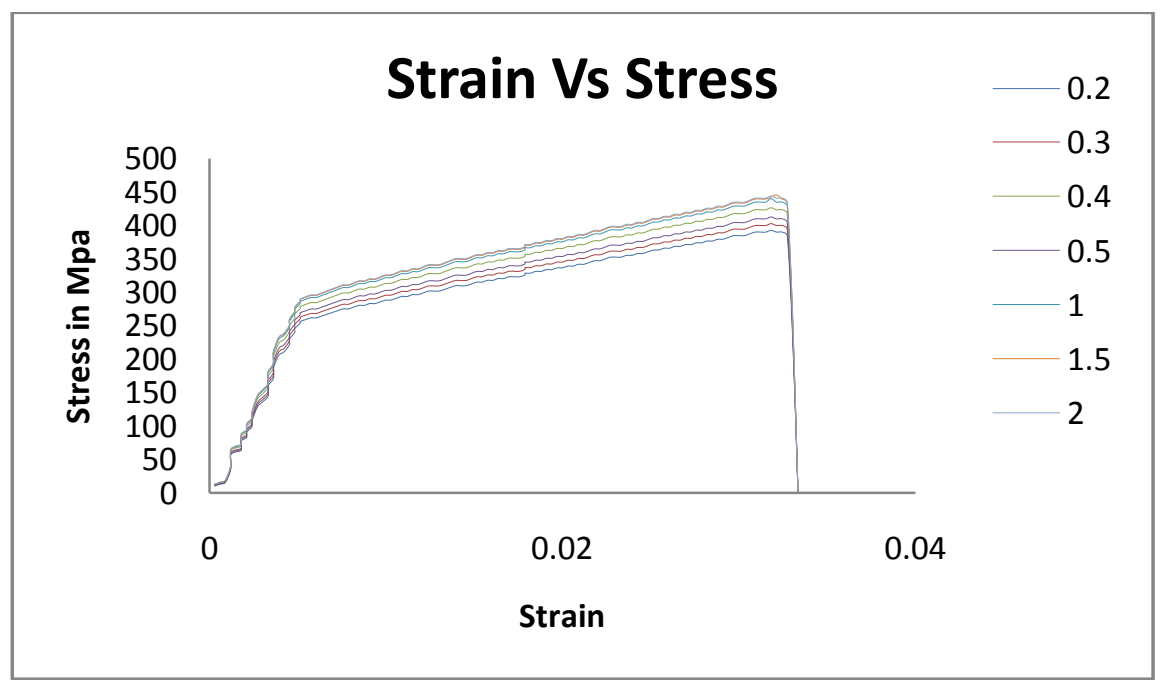

Fig-2 Stress Vs Strain relationship for MMNCs

The Fig-2 shows the stress-strain relationship for various percentages of nano $\mathrm{B}_{4} \mathrm{C}$ particles. The plastic deformation, induced dislocations, or slip dislocations become dominant when the plastic strain exceeds the thermal mismatch strain and the two effects eventually act in combination. The increased yield strength of the MMNCs is due to dislocation generation and accumulation and assuming the dislocations to be uniformly dispersed in the metal matrix. The residual dislocations are likely to be trapped at the reinforcing $\mathrm{B}_{4} \mathrm{C}_{\mathrm{p}}$. This results in local regions of high dislocation density; i.e. the density is highest near the reinforcing $\mathrm{B}_{4} \mathrm{C}_{\mathrm{p}}$ or at the reinforcement matrix interfaces.Fig-3 shows the relation between \%wt of nano particles and strength of the MMNCs. The strength of the MMNCs reduced at $2 \%$ of the nano particulate due the formation of agglomerates in the matrix, failure occurred at the interfaces of the matrix and particulate. 


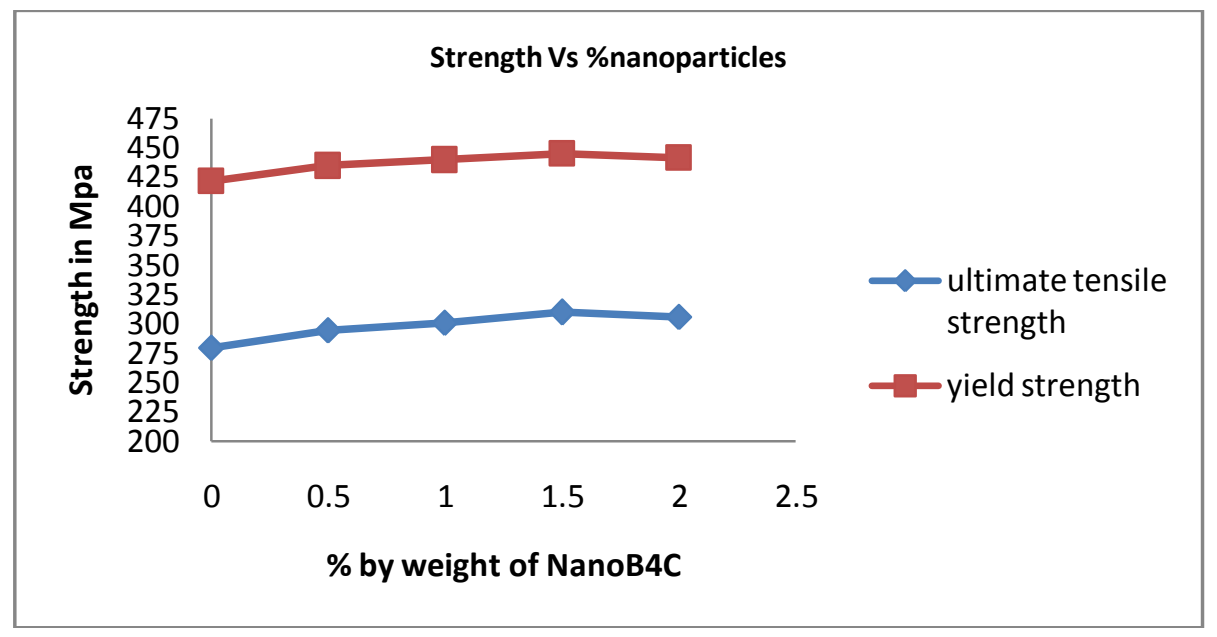

Fig-3 Strength of MMNCs

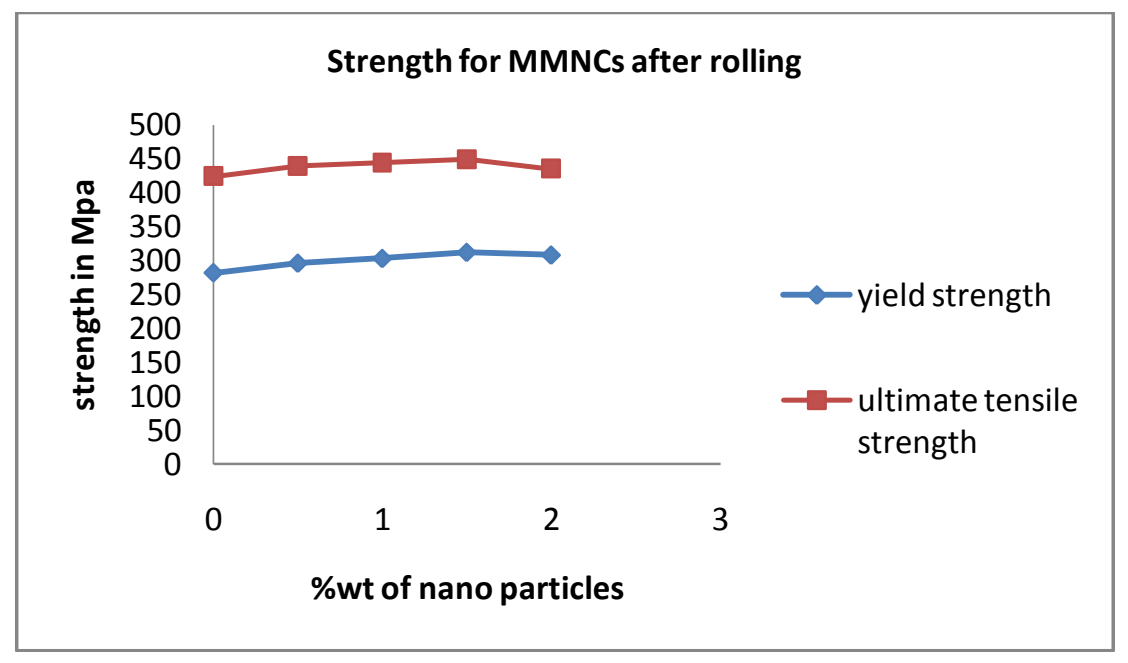

Fig-4 Strength of MMNCs after rolling

3.2.1. DAMAGE DURING TENSILE DEFORMATION: With the influence of tensile load fine microscopic voids appear to grow confirming a possible contribution from particle constraint induced triaxiality on failure of composite matrix. Failure of MMNCs is governed by combined effect of local plastic constraints, particle size and agglomeration. The fracture is highly localized at the discontinuous $\mathrm{B}_{4} \mathrm{C}_{\mathrm{p}}$ reinforcement with the formation of voids. Fracture occurred in the regions of particle clustering due to the enhanced localised stresses resulting from restriction of plastic deformation. The stress immediately adjacent to a reinforcing nano $\mathrm{B}_{4} \mathrm{C}$ particle is a combination of stress components imposed by the macroscopic applied stress and the stress component that developed on a microscopic scale. The microscopic scale components arise as a result of conjoint influence of strain incompatibility between the reinforcing particle and deforming matrix, individual stresses arising from thermal expansion mismatch between the second phase inclusion and the matrix and load sharing by the reinforcing particulates. A combination of thermally induced stress, local stress concentration and macroscopic applied stress and intrinsic brittle nature of reinforcing particle is responsible for cracking. Furthermore, assuming that the aluminium alloy metal matrix- $\mathrm{B}_{4} \mathrm{C}$ particle interfaces are strong, the triaxial stresses generated during far field tensile loading favors limited growth of microscopic voids in the matrix of the composite. The limited growth of voids during far field tensile loading coupled with lack of their coalescence and thus inhibiting the dominant fracture mode to be ductile failure.

\section{Microstructures}

The enhanced properties of the metal matrix nano composites depend on distribution of the reinforcing particles and interface bonding between metal matrix and the dispersed particles. The optical micrograph and 
SEM images of MMNCs reinforced with $1.5 \mathrm{wt} \%$ of nano $\mathrm{B}_{4} \mathrm{C}_{\mathrm{p}}$ are presented in figures below. The optical images of the base metal and MMNCs are shown in Fig-5(a),(b) where the grain boundaries are clearly observed. With the optical microscopy no pores are observed. The grains in Fig 5(a) are larger in size and that of MMNC's are smaller as seen in Fig-5(b).
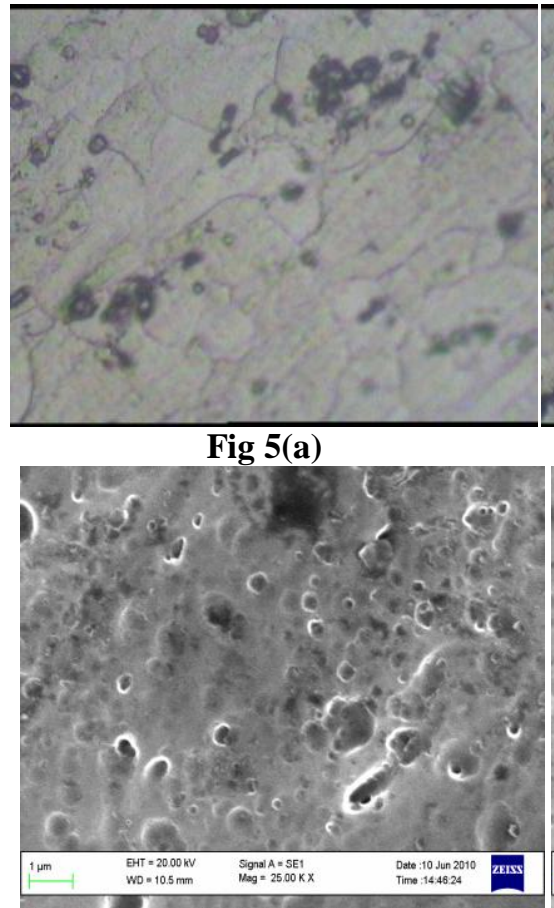

Fig-6(a)

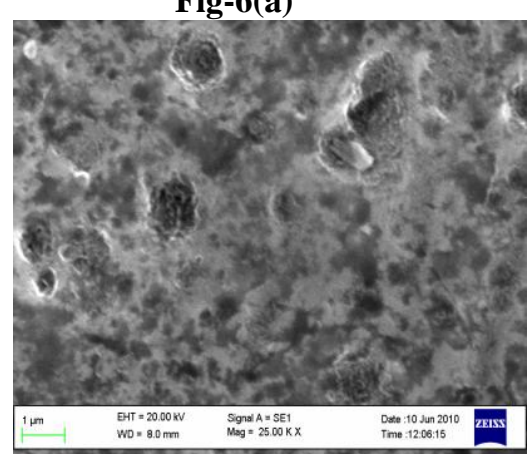

Fig-7
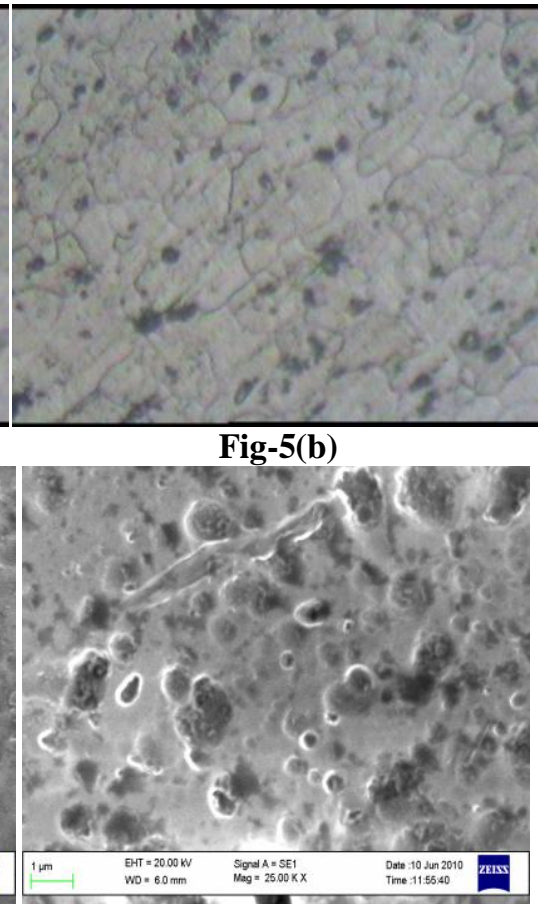

Fig-6(b)

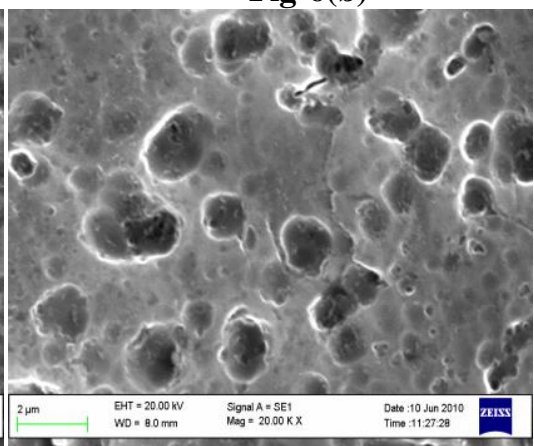

Fig-8

The SEM images of MMNCs reveal that, there is uniform distribution of the nano $\mathrm{B}_{4} \mathrm{C}$ particles in the matrix (Fig-6) and small agglomerates of the powders and voids also be seen at higher magnification Fig-7. The overall microscopic analysis shows that there is good bonding between the matrix and the refractory particulate interface, indicating uniform distribution of particles due to ultrasonic cavitation and grain boundaries are seen distinctly in Fig-8.

\section{Conclusions}

The metal matrix nano composites are fabricated using mechanical stirring and ultrasonic cavitation methods. The effects of nano $\mathrm{B}_{4} \mathrm{C}_{\mathrm{p}}$ dispersion on microstructure and mechanical properties are investigated.

a) The metal matrix nano composites have fine and more homogeneous microstructure with the increase of $\%$ wt of nano $\mathrm{B}_{4} \mathrm{C}_{\mathrm{p}}$ content.

b) The hardness of the aluminum MMNCs improved significantly by the addition of $\mathrm{B}_{4} \mathrm{C}_{\mathrm{p}}$ particles into it.

c) The ultimate tensile strength, yield strength are increased with the increase of $\mathrm{B}_{4} \mathrm{C}_{\mathrm{p}}$ content. The hardness, UTS, Y.S increased by $14 \%, 6 \%, 11 \%$ respectively.

d) Ultrasonic nonlinear affects efficiently disperse nano particles into molten alloy by enhancing their wettability. 


\section{References}

[1]. G. Cao, H. Konishi, X. Li, “Mechanical properties and microstructure of SiC-reinforced Mg-(2,4)Al-1Si nanocomposites fabricated by ultrasonic cavitation based solidification processing”. Materials Science and Engineering A 486 (2008) 357-362.

[2]. Jie Lan, Yong Yang, Xiaochun Li "Microstructure and microhardness of SiC nanoparticles reinforced magnesium composites fabricated by ultrasonic method" Materials Science and Engineering A 386 (2004) 284-290.

[3]. Yong Yang, Jie Lan, Xiaochun Li "Study on bulk aluminum matrix nano-composite fabricated by ultrasonic dispersion of nanosized SiC particles in molten aluminum alloy" Materials Science and Engineering A 380 (2004) 378-383.

[4]. Guoping Cao, Hiromi Konishi, Xiaochun Li "Mechanical Properties and Microstructure of Mg/SiC Nanocomposites Fabricated by Ultrasonic Cavitation Based Nanomanufacturing” Journal of Manufacturing Science and Engineering JUNE 2008 , Vol. 130.

[5]. G. Cao, H. Konishi and X. Li "Recent Developments on Ultrasonic Cavitation Based Solidification Processing of Bulk Magnesium Nanocomposites" International Journal of Metal casting/Winter 08, 57-68.

[6]. Yong Yang, Xiaochun Li, “Ultrasonic Cavitation Based Nanomanufacturing of Bulk Aluminum Matrix Nanocomposites. Journal of Manufacturing Science and Engineering” JUNE 2007, Vol. 129 / 497-501.

[7]. Xiaochun Li et al. "Fundamental Study of Bulk Magnesium Alloy Matrix Nanocomposites Fabricated by Ultrasonic Cavitation Based Solidification Processing” NSF Nanoscale Science and Engineering Grantees Conference, Dec 4-6, 2006.

[8]. S. M. Zebarjad, S. A. Sajjadi and E. Z. Vahid Karimi "Influence of Nanosized Silicon Carbide on Dimensional Stability of Al/SiC Nanocomposite" Research Letters in Materials Science Volume 2008, Article ID 835746, 4 pages.

[9]. A. Mazahery, H. Abdizadeh, H.R. Baharvandi "Development of high-performance A356 nano-Al $2_{2} \mathrm{O}_{3}$ composites" Materials Science and Engineering A 518 (2009) 61-64.

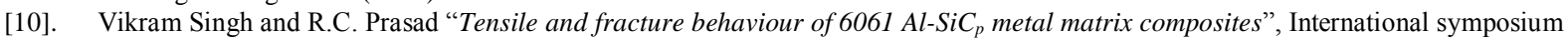
of research students on materials science and engineering, December 20-22, 2004, Chennai, India.

[11]. Lan, J., Yang, Y., and Li, X., 2004, "Microstructure and Microhardness of SiC Nanoparticles Reinforced Composite Fabricated by Ultrasonic Method,” Mater. Sci. Eng., A, 386, 1-2, pp. 284-290.

[12]. Yang, Y., and Li, X., 2007, "Ultrasonic Cavitation Based Nanomanufacturing of Bulk Aluminum Matrix Nanocomposites," ASME J. Manuf. Sci. Eng., 129, pp. 252-255.

[13]. C.F.Deng et.al, 2007, "Processing and properties of carbon nano tubes reinforced aluminium composites", Material Science and Engineering A 444 pp138-145.

[14]. Y.Yang et.al, 2004, "Study on bulk aluminium matrix nano composite fabricated by ultrasonic dispersion of nano sized SiC particles in molten Aluminum alloy”, Material Science and Engineering A380, pp 378-383. 